\title{
Atualização sobre as características da surdez súbita: uma revisão integrativa
}

\author{
Update on the characteristics of sudden deafness: an integrative review
}

Actualización de las características de la sordera repentina: revisión integradora

Laura Pires Ligeiro'* Jemima Ferreira Coelho ${ }^{1 *}$ Ana Silvia Menezes Bastos ${ }^{1}$, Danielle Raphaela Alves $^{2}$, Larissa Silvestre Teixeira Rocha ${ }^{1}$.

\section{RESUMO}

Objetivo: Revisar e sintetizar a problemática da surdez súbita tendo em vista as etiologias, a fisiopatologia, o quadro clínico e o tratamento, levando em consideração as atualizações realizadas sobre o tema. Métodos: Esta revisão de literatura integrativa especializada teve como base um levantamento bibliográfico acerca da surdez neurossensorial. As etapas de construção dessa revisão foram: selecionar a temática e a questão de pesquisa, buscar artigos nas bases de dados digitais, estabelecer critérios de inclusão e exclusão dos artigos, além da discussão dos resultados. Resultados: A patologia apresenta quatro teorias etiológicas: infecção viral, imunológica, ruptura de membranas e distúrbio circulatório. O diagnóstico, por sua vez, é mais fidedigno graças à ressonância magnética, principalmente no Schwannoma vestibular. O tratamento tem como base 0 uso de corticoides e o Implante Coclear (IC). Considerações finais: Considerando a problemática levantada da perda auditiva súbita, ainda que existam inúmeros posicionamentos divergentes dos autores, há um consenso sobre o uso de corticosteroides que mostrou diminuir o tempo de doença e uso da ressonância magnética para estabelecer o diagnóstico e prognóstico da doença além de elucidar outros possíveis diagnósticos diferenciais.

Palavras-chave: Surdez súbita, Perda auditiva súbita, Surdez neurossensorial.

\begin{abstract}
Objective: To synthesize the problem of sudden deafness in view of the etiologies, pathophysiology, clinical picture and treatment; taking into account the updates made on the topic. Methods: This review of the specialized integrative literature was based on a bibliographic survey about sensorineural deafness. The stages of construction of this review were: to select the issue and the research question, to search for articles in the digital databases, to establish criteria for inclusion and exclusion of the articles, in addition to discussing the results. Results: The pathology presents four etiological theories: viral, immunological infection, rupture of membranes and circulatory disorder. The diagnosis, in turn, is more reliable thanks to magnetic resonance imaging, especially in vestibular schwannoma. In addition, the treatment is based on the use of corticosteroids and the Cochlear Implant (Cl). Final considerations: Considering the problem raised by sudden hearing loss, although there are numerous divergent positions of the authors, there is a consensus on the use of corticosteroids that has shown to decrease the time of disease and use of magnetic resonance imaging to establish the diagnosis and prognosis of the disease in addition to elucidating other possible differential diagnoses.
\end{abstract}

Key words: Sudden deafness, Sudden hearing loss, Sensorineural deafness.

\footnotetext{
${ }^{1}$ Universidade de Vassouras (UV), Vassouras - RJ.

*E-mail: piresligeiro98@gmail.com

${ }^{2}$ Centro Universitário do Espírito Santo (UNESC), Colatina - ES.
}

SUBMETIDO EM: 6/2021

ACEITO EM: 6/2021

PUBLICADO EM: 7/2021 


\section{RESUMEN}

Objetivo: Sintetizar el problema de la sordera súbita en vista de las etiologías, fisiopatología, cuadro clínico y tratamiento; teniendo en cuenta las actualizaciones realizadas sobre el tema. Métodos: Esta revisión de la literatura integrative especializada se basó en una encuesta bibliográfica sobre sordera neurosensorial. Las etapas de construcción de esta revisión fueron: seleccionar el tema y la pregunta de investigación, buscar artículos en las bases de datos digitales, establecer criterios de inclusión y exclusión de los artículos, además de discutir los resultados. Resultados: La patología presenta cuatro teorías etiológicas: viral, infección inmunológica, rotura de membranas y trastorno circulatorio. El diagnóstico, a su vez, es más fiable gracias a la resonancia magnética, especialmente en el schwannoma vestibular. Además, el tratamiento se basa en el uso de corticoides y el Implante Coclear (IC). Consideraciones finales: Considerando el problema que plantea la pérdida súbita de audición, aunque existen numerosas posiciones divergentes de los autores, existe un consenso sobre el uso de corticoides que ha demostrado disminuir el tiempo de enfermedad y el uso de la resonancia magnética para establecer el diagnóstico y pronósticode la enfermedad además de dilucidar otros posibles diagnósticos diferenciales.

Palabras clave: Sordera súbita, Pérdida súbita de audición, Sordera neurosensorial.

\section{INTRODUÇÃO}

A Surdez Súbita (SS) é definida como uma perda auditiva neurossensorial maior que 30 decibéis em pelo menos três frequências adjacentes, que tenha uma instalação súbita ou que tenha duração máxima de 3 dias, e representa um sintoma sem uma etiologia própria (YOUNG YI-HO, 2020; HERRERA M, et al., 2018). Em súmula, a SS pode ser definida como um sintoma à procura de um diagnóstico (LI G, et al., 2018). Em 85\% dos casos descritos de SS, a etiologia da doença é desconhecida, sendo enquadrada como idiopática, o que leva ao tratamento empírico. Nesse sentido, pode-se afirmar que a SS é um sintoma presente em mais de sessenta doenças diferentes, que variam desde o Schwanoma Vestibular (SV) até a Hemorragia Intralabiríntica (BARRETO MASC, et al., 2016).

Por não apresentar uma entidade nosológica própria, e, atrelado a isso, propiciando o baixo conhecimento da doença pelos especialistas, a SS acaba por ser ainda um dos maiores assuntos de debate entre os otorrinolaringologistas. Os mecanismos que levam à SS ainda não foram desvendados e a perda súbita da audição pode variar entre leve a muito severa e sua recuperação pode ser espontânea em $25 \%$ ou mais casos. Por isso, a discussão se inicia na sua definição e continua até seu tratamento, afinal a SS pode deixar sequelas auditivas irreversíveis, ter recuperação total, até mesmo de forma espontânea (CHANDRASEKHAR SS, et al., 2019; BARRETO MAS e JR FB, 2013).

A deficiência auditiva se destaca dentre as deficiências físicas como uma daquelas que pode acometer o indivíduo em qualquer fase da vida. Dessa forma, impossibilita o desempenho de atividades sociais pelos cidadãos, fazendo com que haja uma tendência ao isolamento social, à alteração do planejamento de vida e, não menos importante, ocasionando estresse familiar. É essencial entender a origem da SS e poder, assim, buscar uma solução específica para a questão, visto que é de vital importância para a manutenção da comunicação e da inclusão social do paciente (AMARAL MSA, et al., 2019; SCARABELLO EM, et al., 2020; OLIVEIRA WSR, et al., 2020).

A SS é uma área da otorrinolaringologia de grandes debates, entretanto, uma terapêutica certeira é o implante coclear (IC). O dispositivo é, sempre que possível, de extrema importância, principalmente para os pacientes de perda auditiva pré-lingual, uma vez que possibilita a reabilitação auditiva e a qualidade de vida do paciente (AHMADZAI N, et al., 2018; MARTINS MBB, et al., 2012). Contudo, há um processo pelo qual os deficientes devem passar para a realização do implante, como: análise pré-cirúrgica, ato cirúrgico e restauração auditiva (MARTINS MBB, et al., 2012).

Por fim, esses grandes estudos sobre a SS são de extrema importância para que a patologia seja melhor compreendida e tenha melhor manejo. Conhecer de forma detalhada a fisiopatologia da doença contribui para 
a diminuição do número de pacientes com sequelas auditivas permanentes. Sendo assim, o objetivo do presente estudo é discorrer acerca da SS e suas diversas opções de tratamento, de forma a contribuir para a implementação de um protocolo médico especializado, visando um melhor prognóstico da doença.

\section{MÉTODOS}

Este artigo se baseia em uma revisão de literatura do tipo integrativa, cuja questão explorada foi a Surdez Súbita. Os estágios de produção que se sucederam foram: escolha do tema e questão de pesquisa. Na busca dos artigos nas bases de dados digitais, foram estabelecidos os critérios de inclusão e exclusão de estudos, e posteriormente, foi feita a análise com discussão dos resultados apresentados pelos periódicos. As bases de dados digitais utilizadas foram: PubMed, Scientific Electronic Library Online (Scielo) e Acervo+, utilizando os seguintes descritores: Perda Auditiva Súbita, Surdez Súbita e Surdez Neurossensorial, em português e inglês. Foi aplicada uma filtragem temporal de 2013 a 2021. Foram encontrados, no PubMed, um total de trezentos e sessenta e um artigos, sendo selecionados apenas aqueles de acordo com a relevância para o tema. Na base de dados Scielo e PebMed, as buscas resultaram em sete e dez artigos, respectivamente, e na base Acervo+, três artigos. Foram selecionados artigos em português, inglês e espanhol.

De todos os arquivos encontrados nas duas bases de dados, foram excluídos as duplicatas, relatos de caso e artigos que não se enquadram no tema proposto, sendo utilizados apenas 20 artigos em português, inglês e espanhol de caráter eletrônico. Foram utilizados como critérios de inclusão: artigos baseados em evidências, consensos e diretrizes que tivessem como questão norteadora o diagnóstico e tratamento da patologia, bem como suas possíveis repercussões para a qualidade de vida do paciente. Foram excluídos artigos que tangenciassem o tema ou que os descritores não estavam correlacionados à proposta da pesquisa. Além disso, todas as referências dos 20 periódicos selecionados foram analisadas por completo, a fim de ampliar o arcabouço teórico deste estudo (Figura 1).

A análise de conteúdo aconteceu em três etapas de seleção. A primeira teve a procura pelo seguinte termo: surdez súbita. A segunda foi por meio do título e resumo e a terceira pela qualificação dos artigos. Para a primeira etapa houve a seleção dos textos sobre a temática. Na segunda, houve a leitura e enquadramento de quais seriam viáveis para o objetivo principal. E na terceira triagem, os artigos foram lidos e selecionados para o fim maior, que é atender os critérios de elegibilidade.

Figura 1 - Fluxograma da seleção dos estudos para esta revisão.

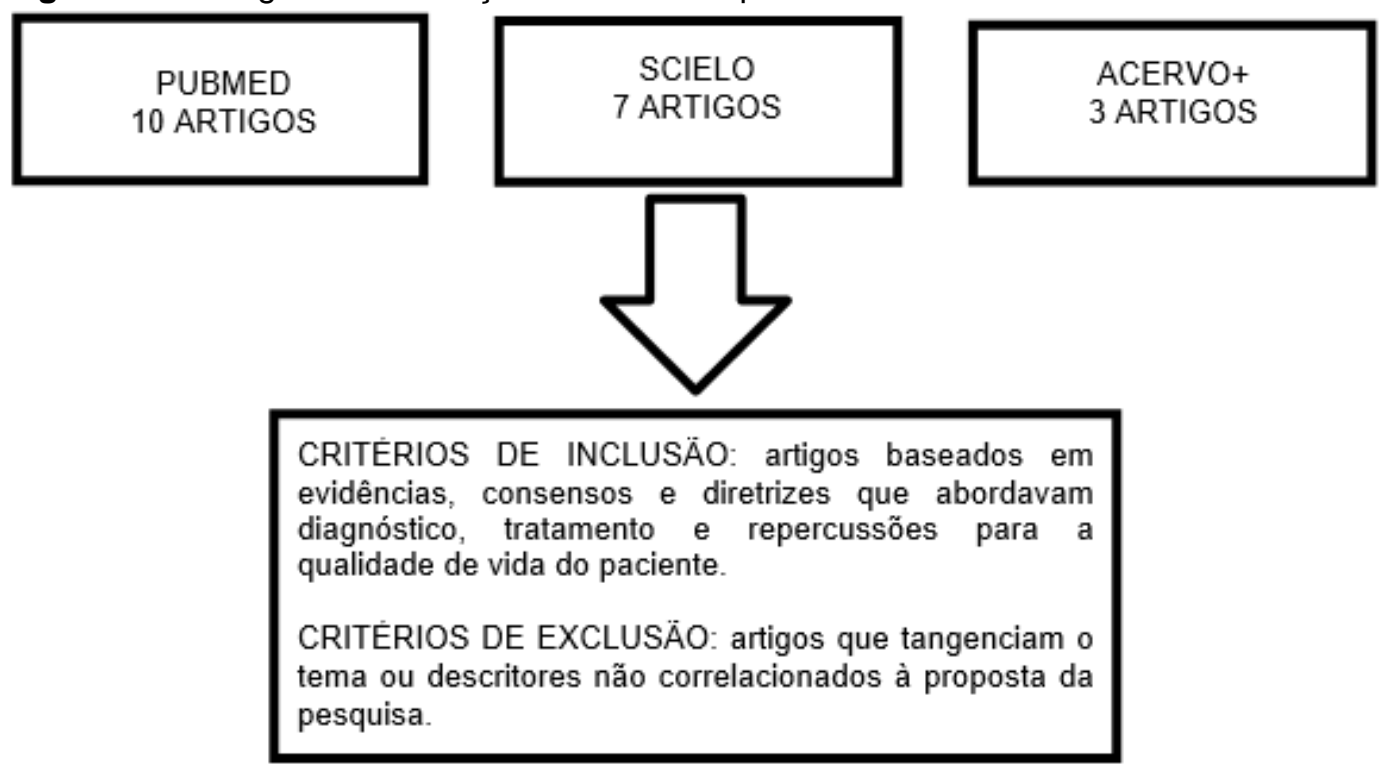

Fonte: Ligeiro LP, et al., 2021. 


\section{RESULTADOS}

Foram analisados vinte artigos, onde se pode inferir que a SS é uma patologia multi etiológica, sendo necessária a análise do caso individual do paciente. A SS traz um grande incômodo para os pacientes, visto que se trata de um dos cinco sentidos humanos, tendo grande impacto na qualidade de vida e até comprometimento da socialização destes. Pode também estar associado à cronificação do quadro e complicações, a depender da etiologia. No que se refere ao diagnóstico da SS é imperativo delimitar bem o quadro por meio da anamnese e exame físico, e, se oportuno, realizar exames complementares. Sobre o tratamento ainda não possui um padrão ouro descrito em literatura médica especializada. Alguns consensos e protocolos sugerem o emprego de corticoides, drogas vasodilatadoras, anticoagulantes e, em casos que evoluem com deterioração permanente da audição, o Implante Coclear (IC) (AKIL F, et al., 2018).

É importante que o profissional de saúde detenha a capacidade de reconhecer os sinais e sintomas esclarecidos no presente artigo para que as providências corretivas sejam tomadas de forma imediata, poupando a qualidade de vida do paciente envolvido (AMARAL MSA, et al., 2019).

De todas as informações colhidas em todos os artigos, observou-se que, mesmo em diferentes tipos de estudos, a propedêutica demonstrou pouca divergência entre si; ou seja, a discussão sobre sintomatologia, perfil epidemiológico, diagnóstico e uso de exames complementares, se somaram (BARRETO MASC, et al., 2016). Isso pode ser comprovado pelos dados que foram dispostos em formato de quadro para título de comparação (Quadro 1). 
Quadro 1 - Resultados obtidos após análise dos periódicos.

\begin{tabular}{|c|c|c|c|c|}
\hline Título & Autor (Ano) & Sintomas & $\begin{array}{c}\text { Exame } \\
\text { Complementar }\end{array}$ & Tratamento \\
\hline $\begin{array}{c}\text { Investigação da proporção de } \\
\text { neutrófilos para linfócitos e volume } \\
\text { plaquetário médio na perda auditiva } \\
\text { súbita }\end{array}$ & Kum RO, et al., 2015 & Surdez súbita & Hemograma & - \\
\hline $\begin{array}{l}\text { Desenvolvimento e aplicação de uma } \\
\text { tecnologia educacional para auxiliar a } \\
\text { comunicação entre o deficiente auditivo } \\
\text { e enfermeiro: relato de experiência. }\end{array}$ & $\begin{array}{l}\text { Oliveira WSR, et al., } \\
\qquad 2020\end{array}$ & Deficiente auditivo & - & - \\
\hline $\begin{array}{l}\text { Desenvolvimento da linguagem em } \\
\text { crianças com implante coclear: terá o } \\
\text { gênero alguma influência? }\end{array}$ & Ramos D, et al. 2015 & $\begin{array}{l}\text { Surdez severa a profunda } \\
\text { neurossensorial }\end{array}$ & - & - \\
\hline $\begin{array}{c}\text { Uma comparação de esteróides orais } \\
\text { de dose única e múltiplas doses diárias } \\
\text { divididas para perda auditiva } \\
\text { neurossensorial súbita }\end{array}$ & Yu GH, et al. 2019 & Surdez súbita & - & Corticoide \\
\hline $\begin{array}{c}\text { Avaliação da linguagem em crianças } \\
\text { com perda auditiva pré-lingual e } \\
\text { implante coclear }\end{array}$ & $\begin{array}{l}\text { Scarabello EM, et al. } \\
\qquad 2020\end{array}$ & $\begin{array}{l}\text { Surdez súbita, perda } \\
\text { auditiva pré lingual }\end{array}$ & - & Implante coclear \\
\hline $\begin{array}{l}\text { Injeção intratimpânica de esteroides e } \\
\text { oxigenoterapia hiperbárica para o } \\
\text { tratamento da surdez súbita refratária }\end{array}$ & $\begin{array}{l}\text { Gülüstan F, et al. } \\
\qquad 2016\end{array}$ & $\begin{array}{l}\text { Perda auditiva } \\
\text { neurosensorial súbita }\end{array}$ & - & $\begin{array}{l}\text { Oxigênia hiperbárico, esteróide } \\
\text { intratipâncio }\end{array}$ \\
\hline $\begin{array}{l}\text { Implantes cocleares: nossa experiência } \\
\text { e revisão da literatura }\end{array}$ & $\begin{array}{l}\text { Martins MBB, et al. } \\
\qquad 2012 .\end{array}$ & Deficiência auditiva & $\begin{array}{l}\text { Ressonância } \\
\text { Magnética e } \\
\text { Tomografia } \\
\text { Computadorizada }\end{array}$ & Implante coclear \\
\hline $\begin{array}{c}\text { O lugar da oxigenoterapia hiperbárica e } \\
\text { da terapia com ozônio na perda auditiva } \\
\text { súbita }\end{array}$ & $\begin{array}{l}\text { Tasdöven GE, et al. } \\
2016 .\end{array}$ & $\begin{array}{l}\text { Surdez sensorioneural } \\
\text { súbita }\end{array}$ & - & $\begin{array}{c}\text { Oxigenoterapia hiperbárica, terapia com } \\
\text { ozônio e corticoides }\end{array}$ \\
\hline $\begin{array}{l}\text { Inibidores da fosfodiesterase tipo } 5 \text { e } \\
\text { perda auditiva neurossensorial súbita }\end{array}$ & $\begin{array}{l}\text { Barreto MASC, et al. } \\
2013\end{array}$ & $\begin{array}{l}\text { Hipoacusia, zumbido e } \\
\text { vertigem intensa }\end{array}$ & $\begin{array}{l}\text { Ressonância } \\
\text { Magnética. }\end{array}$ & Inibidores da fosfodiesterase tipo 5 \\
\hline $\begin{array}{c}\text { Potenciais evocados miogênicos } \\
\text { vestibulares no prognóstico da perda } \\
\text { auditiva súbita - uma revisão } \\
\text { sistemática }\end{array}$ & $\begin{array}{l}\text { Maia NPD, et al. } \\
2020\end{array}$ & $\begin{array}{l}\text { Surdez súbita, vertigem e / } \\
\text { ou tontura associada. }\end{array}$ & $\begin{array}{l}\text { Tomografia } \\
\text { computadorizada } \\
\text { e ressonância } \\
\text { magnética }\end{array}$ & - \\
\hline
\end{tabular}




\begin{tabular}{|c|c|c|c|c|}
\hline Título & Autor (Ano) & Sintomas & $\begin{array}{c}\text { Exame } \\
\text { Complementar }\end{array}$ & Tratamento \\
\hline $\begin{array}{c}\text { Corticosteroide intratimpânico para } \\
\text { perda auditiva súbita: realmente } \\
\text { funciona }\end{array}$ & $\begin{array}{l}\text { Barreto MASC, et al. } \\
\qquad 2016\end{array}$ & Surdez súbita & Audiometria tonal & Corticosteroide oral \\
\hline $\begin{array}{c}\text { O impacto do implante coclear em } \\
\text { paciente com perda auditiva severa: } \\
\text { uma revisão bibliográfica. }\end{array}$ & Costa TN, et al. 2020 & Perda auditiva severa & - & - \\
\hline $\begin{array}{c}\text { A acessibilidade nos serviços de saúde } \\
\text { sob a perspectiva da pessoa com } \\
\text { deficiência. }\end{array}$ & $\begin{array}{l}\text { Carvalho MEL, et al. } \\
\qquad 2020\end{array}$ & $\begin{array}{l}\text { Perspectiva da pessoa com } \\
\text { deficiência }\end{array}$ & - & - \\
\hline $\begin{array}{c}\text { Revisão contemporânea das causas e } \\
\text { diagnóstico diferencial da perda auditiva } \\
\text { neurossensorial súbita }\end{array}$ & Yong YI-HO, 2020. & $\begin{array}{c}\text { Perda auditiva } \\
\text { neurossensorial súbita. }\end{array}$ & $\begin{array}{l}\text { Ressonância } \\
\text { Magnética e teste } \\
\text { de orelha interna }\end{array}$ & - \\
\hline $\begin{array}{l}\text { Diretriz de prática clínica: perda auditiva } \\
\text { súbita (atualização) }\end{array}$ & $\begin{array}{l}\text { Chandrasekhar SS, } \\
\text { et al. } 2019\end{array}$ & Surdez súbita & $\begin{array}{l}\text { Audiometria e } \\
\text { ressonância } \\
\text { magnética }\end{array}$ & $\begin{array}{c}\text { Corticosteroide e oxigenoterapia } \\
\text { hiperbárica }\end{array}$ \\
\hline $\begin{array}{l}\text { Cirurgias de revisão de implante coclear } \\
\text { em crianças }\end{array}$ & $\begin{array}{l}\text { Amaral MSA, et al. } \\
2019\end{array}$ & $\begin{array}{l}\text { Surdez sensorioneural } \\
\text { profunda }\end{array}$ & - & - \\
\hline $\begin{array}{l}\text { Um protocolo para uma meta-análise de } \\
\text { rede de intervenções para tratar } \\
\text { pacientes com perda auditiva } \\
\text { neurossensorial súbita }\end{array}$ & $\begin{array}{l}\text { Ahmadzai N, et al. } \\
\qquad 2018\end{array}$ & $\begin{array}{l}\text { Perda auditiva } \\
\text { neurossensorial súbita. }\end{array}$ & - & $\begin{array}{c}\text { Esteróides sistemáticos, antivirais, } \\
\text { expansão de volume } \\
\text { sistêmica, antitrombóticos, vasodilatadores, } \\
\text { terapias de oxigenação de } \\
\text { tecidos aumentadas, terapias de } \\
\text { combinação de esteróides intratimpânicos, } \\
\text { terapias antiinflamatórias, vasodilatação } \\
\text { antiplaquetária }\end{array}$ \\
\hline $\begin{array}{c}\text { Atualização do consenso sobre o } \\
\text { diagnóstico e tratamento da surdez } \\
\text { súbita idiopática }\end{array}$ & $\begin{array}{l}\text { Herrera M, et al. } \\
2018\end{array}$ & Surdez súbita & $\begin{array}{l}\text { Ressonância } \\
\text { magnética }\end{array}$ & Corticosteroide \\
\hline $\begin{array}{c}\text { O papel da autoimunidade na } \\
\text { patogênese da perda auditiva } \\
\text { neurossensorial súbita }\end{array}$ & Li G, et al. 2018 & $\begin{array}{l}\text { Perda auditiva } \\
\text { neurossensorial súbita }\end{array}$ & - & Glicocorticoide \\
\hline $\begin{array}{c}\text { Perda auditiva súbita bilateral idiopática } \\
\text { simultânea - características e resposta } \\
\text { ao tratamento. }\end{array}$ & Akil F, et al. 2018 & Perda auditiva súbita & $\begin{array}{l}\text { Ressonância } \\
\text { magnética }\end{array}$ & Esteroides orais \\
\hline
\end{tabular}

Legenda: -: Informações não encontradas nos artigos. Fonte: Ligeiro LP, et al., 2021. 


\section{DISCUSSÃO}

A SS é uma doença que exige muita atenção e dedicação do otorrinolaringologista. Por não apresentar uma entidade nosológica própria, foram realizados diversos estudos histopatológicos que permitiram a criação de quatro teorias para tentar explicar a fisiopatologia da SS. As teorias são: infecção viral, imunológica, ruptura de membranas e distúrbio circulatório. As duas primeiras hipóteses são as mais bem aceitas, já as duas últimas ainda são objetos de muito estudo (KUM RO et al., 2015; CARVALHO MEL, et al., 2020)

A teoria imunológica tem como base que as células da orelha interna são acometidas por complexos imunológicos de doenças sistêmicas. Outros autores acreditam que o vírus é capaz de sintetizar uma ação citotóxica direta sobre as células sensoriais da cóclea e, assim, induzir a produção de complexos imunes. A teoria vascular, por sua vez, é baseada na falta de suprimento nas células sensoriais da orelha interna que gera uma isquemia cócleo-labiríntica e, com isso, há morte de células de estruturas nobres (KUM RO et al., 2015).

A hipótese vascular aponta a vulnerabilidade da cóclea a anoxia. Estudos experimentais foram realizados e concluíram que uma obstrução de 60 segundos é capaz de ocasionar uma diminuição dos potenciais cocleares; se o fechamento for menor que oito minutos, ela se recupera completamente, mas estes potenciais ocorrem se o tempo de oclusão for maior que 60 minutos. Um fator fisiopatológico vascular observado é hiperviscosidade sanguínea que promove a queda do fluxo sanguíneo e consequentemente leva à hipóxia tecidual. Há estudos de doentes com SS em que foram observadas as características sanguíneas e plasmáticas, comparados com grupos controles normais, que demonstraram valores superiores nos portadores de SS (AKIL F, et al., 2018).

Nesse contexto, na teoria vascular tem-se outros mecanismos a serem citados, como o acontecimento de tromboses e embolias que, consequentemente, geram a isquemia coclear. A vascularização da orelha média é do tipo terminal, ou seja, qualquer obstrução, completa ou parcial do fluxo sanguíneo, imediatamente afeta na fisiologia oxidativa do ouvido. A obstrução gera hipóxia/anoxia celular, o que conduz a uma queda na síntese de ATP, arsenal de radicais livres e de acidose intracelular. Estes três últimos fatores citados modificam o sistema enzimático da célula e produzem necrose e morte celular (AKIL F, et al., 2018).

A hemorragia labiríntica é uma das causas da etiologia vascular e pode ser observada em pacientes com anemia aplásica, anemia falciforme, leucemias, secundária a trauma cranioencefálico, após tratamento cirúrgico de SV e até em pacientes com hematopatias e/ou em terapia com anticoagulantes. Cursa com uma alteração na pressão hidrostática que modifica o funcionamento e a estimulação nervosa da cóclea, devido à presença de sangue, endolinfa e perilinfa. A Ressonância Magnética (RM) permite o diagnóstico preciso caso haja gordura presente na perilinfa; e a endolinfa, além do baixo fluxo sanguíneo, altas concentrações proteicas e a presença de metemoglobina, produz imagens hiperintensas (MARTINS MBB, et al., 2012).

A hipótese viral é categoricamente acatada, pois existem muitos vírus causadores de surdez congênita e de surdez sensório-neural abrupta, tais como o Paramyxovirus da caxumba, o vírus da rubéola e da família Herpesviridae. Há uma divergência de estudos; um defende a teoria de que a SS foi precedida pela infecção de vias aéreas superiores em um mês. Em outro, é proposto que a ocorrência de indícios de vias aéreas superiores prévias é igual quando se relaciona conjuntos de doentes com SS de uma população em geral, ou seja, não há relação entre a infecção com a SS (MARTINS MBB, et al., 2012).

Outra tese é a da ruptura da membrana da orelha interna, onde é afirmado que há uma interrupção da membrana do labirinto membranoso. Segundo essa teoria, a interrupção de uma das janelas labirínticas levaria a uma eliminação de perilinfa da orelha interna para a orelha média, ocasionando uma grande desproporção da pressão entre os compartimentos endolinfáticos e perilinfáticos, acarretando uma perda da membrana de Reissner. A segunda lesão geraria um encontro da perilinfa com a endolinfa, que prejudicaria a fisiologia da cóclea. A cicatrização dessas membranas ajudaria na reabilitação das estruturas cocleares com consequente recuperação auditiva (MAIA NPD, et al., 2020).

O Schwanoma Vestibular (SV) é um tumor benigno que tem uma grande variedade de apresentações; vai desde assintomático até quadros neurológicos dramáticos, sendo hoje uma das causas de SS a ser 
investigada. Porém, quando se analisa o inverso, este não se prova verdadeiro, pois dos pacientes com SS, apenas $1 \%$ tem a chance de ter SV. O maior obstáculo é descobrir, dentre estes, quais são decorrentes de SV, já que são escassas as características patognomônicas. A pluralidade das apresentações sintomáticas se mostra com sintomas auditivos e vestibulares, podendo também apresentar manifestações trigeminais e faciais. O quadro da SS no SV decorre da compressão do oitavo par craniano pela massa tumoral. Com isso, o nervo vestíbulo coclear que apresenta uma zona de transição da mielinização em que a bainha de mielina das células de Schwann se encontra com os oligodendrócitos, passa a sofrer devido à pouca vascularização e desmielinização. A compressão desta área pode favorecer a neuropatia reversível por bloqueio da condução nervosa do oitavo par (BARRETO MASC, et al., 2016).

A relação do SV com a SS se dá por meio do tamanho do tumor, porém, questiona-se o fato de nem todo tumor grande cursar com SS. A maior associação, se encontra, de fato, relacionada à localização do tumor dentro ou fora do Meato Auditivo Interno (MAI). O diagnóstico da SS secundaria ao SV representa uma dificuldade para os médicos, uma vez que não existe um sinal característico da doença que a aponte como causa. O que se sabe é que pacientes mais jovens com SS possuem maior probabilidade de tê-la de forma secundária ao SV e que o quadro tende a ser mais leve com melhor prognóstico se comparado à SS de outra etiologia. Além disso, a melhora da SS, independente de tratamento, não exclui a pesquisa de SV. Sua melhora, mesmo que rara, ainda é possível ocorrer, seja de forma parcial ou total; outro ponto é com relação ao uso de Corticosteroides (CE), que propiciam melhora nos pacientes (BARRETO MASC, et al., 2016).

Dentre os exames complementares para a análise de SV, a audiometria de tronco cerebral é considerada o exame eletrofisiológico mais sensível para o diagnóstico, com índices de falso-negativos de 5\% ou menos. Entretanto, a RM ainda é o exame de eleição, possuindo alta sensibilidade e alta especificidade. Alguns autores ainda preconizam a RM na investigação radiológica da orelha interna, do nervo vestíbulo coclear e do sistema nervoso central, e nos pacientes com SS ela se justifica, pois tem alto índice para detecção de lesões até então não diagnosticadas, como o SV, o que acaba por suplementar o seu custo (AKIL F, et al. 2018).

Acerca da terapêutica para SS, assim como a etiologia não tem uma causa específica, o tratamento também não tem um propósito próprio. Alguns autores afirmam que não existem evidências de que uma terapêutica gere melhora significativa. Outros autores acreditam que a surdez súbita não necessita de tratamento, pois se trata de uma patologia autolimitada (KUM RO, et al., 2015).

Por outro lado, existem trabalhos com grupo controle que mostraram que apenas os CE têm algum efeito benéfico na medicação da SS. Ademais, os vasodilatadores, apesar de serem amplamente utilizados, ainda carecem de mais estudos controle mais rígidos que comprovem seus efeitos positivos no tratamento. No estudo deste artigo, a opção pelo uso de prednisona associada à pentoxifilina ocorreu, pois ambas eram de uso ambulatorial, evitando assim os inconvenientes de uma hospitalização e diminuindo os potenciais de risco com o uso do vasodilatador ou CE endovenosos (YU GH, et al., 2019).

Os CE são os mais utilizados pelos otorrinolaringologistas; sua prescrição é simples devido ao fácil manuseio, além do baixo custo e da possibilidade de terapêutica domiciliar. Em união com os corticoides, os vasodilatadores têm muita aceitação na prática médica, uma vez que o tratamento é baseado na hipótese vascular. Visa melhorar a perfusão sanguínea da cóclea, favorecendo também as condições metabólicas e a capacidade de regeneração do órgão em decadência (BARRETO MASC, et al., 2016).

A oxigenoterapia hiperbárica se baseia na promoção do aumento do nível de oxigênio sanguíneo. Houve diversos estudos que apontam que a oxigenoterapia pode ser utilizada isoladamente ou em associação a outro tratamento. Segundo alguns autores, essa terapia é mais utilizada quando já se tentou outros tratamentos sem sucesso. Assim como a oxigenoterapia hiperbárica, o uso de anti-hipertensivos, anticoagulantes, CE, expansores plasmáticos e as medidas higiênico-dietéticas não são comprovadamente maiores que a cura espontânea (TASDÖVEN GE, et al., 2017; GÜLÜSTAN F, et al., 2016).

Outra opção de tratamento é o IC proposto para perdas auditivas definitivas. Por definição, o IC é um dispositivo eletrônico que permite a reabilitação auditiva de indivíduos com disacusia neurossensorial severa 
a profunda, bilateral, sem melhora com o uso de aparelho de amplificação sonora individual (MARTINS MBB, et al., 2012; RAMOS D, et al., 2015).

O processo de IC, apesar de ter sido amplamente difundido nas últimas décadas, não é simples. $O$ paciente precisa passar por várias etapas para conseguir recuperar a sua função auditiva. Essas etapas vão desde a avaliação pré-cirúrgica e 0 ato cirúrgico até a reabilitação, realizada pelo fonoaudiólogo em acompanhamento com o otorrinolaringologista para análise da evolução do paciente. Existem alguns fatores que influenciam a evolução da terapêutica, tais como a idade no momento da cirurgia, o tempo de privação sensorial e o tempo de uso do implante. A idade tem sido muito analisada, principalmente nas crianças que realizam o implante antes dos três anos. Afinal, é preciso, pelo menos, dois anos de uso do implante para ter resultados satisfatórios (MARTINS MBB, et al., 2012; COSTA TN, et al., 2020).

Por último, não se pode esquecer das implicações sociais que a deficiência auditiva pode gerar tanto para o deficiente, quanto para sua família. Isso afeta a maneira como a pessoa é vista devido ao estigma intrínseco da deficiência auditiva, uma vez que a maioria dos locais de trabalho e de socialização ainda não está preparado para receber esses cidadãos que não têm locais específicos de treinamento e isso dificulta para 0 surdo mostrar o seu potencial (COSTA TN, et al., 2020).

\section{CONSIDERAÇÕES FINAIS}

Diante do exposto, reitera-se que a SS ainda carece de muita discussão sobre as suas etiologias e principalmente sobre a terapêutica, visto os inúmeros posicionamentos divergentes dos autores encontrados. Sendo assim, é importante realizar um estudo randomizado de relevância, visto que há uma carência de publicações recentes sobre o tema. Dessa forma, será possível idealizar um protocolo de manejo terapêutico onde o paciente possa se recuperar o mais rápido possível, para que não evolua com complicações ou que tenha sequelas permanentes, além de atualizar o banco de dados com estudos mais recentes e precisos sobre a temática abordada.

\section{REFERÊNCIAS}

1. AHMADZAI N, et al. A protocol for a network meta-analysis of interventions to treat patients with sudden sensorineural hearing loss. Revisões Sistemáticas, 2018; 7(74): 1-8.

2. AKIL F, et al. Simultaneous idiopathic bilateral sudden hearing loss- characteristics and response to treatment. Brazilian Journal of Otorhinolaryngology, 2018; 78(1).

3. AMARAL MSA, et al. Cochlear implant revision surgeries in children. Braz J Otorhinolaryngol, 2019; 85(3).

4. BARRETO MASC, et al. Intratympanic corticosteroid for sudden hearing loss: does it really work?. Braz J Otorhinolaryngol, 2016; 82(3): 353-364.

5. BARRETO MASC, Jr FB. Phosphodiesterase type 5 inhibitors and sudden sensorineural hearing loss. Braz $\mathrm{J}$ Otorhinolaryngol, 2013; 79(6): 727-33.

6. CHANDRASEKHAR SS, et al. Clinical Practice Guideline: Sudden Hearing Loss (Update). Academy of Otolaryngology, 2019; 161(15): 1-45.

7. CARVALHO MEL, et al. A acessibilidade nos serviços de saúde sob a perspectiva da pessoa com deficiência. Revista Eletrônica Acervo Saúde, 2020; 12 (1).

8. COSTA TN, et al. O impacto do implante coclear em paciente com perda auditiva severa: uma revisão bibliográfica. Revista Eletrônica Acervo Cientifico, 2020; 14.

9. GÜLÜSTAN F, et al. Intratympanic steroid injection and hyperbaric oxygen therapy for the treatment of refractory sudden hearing loss. Braz J Otorhinolaryngol, 2016; 84: 28-33.

10. HERRERA M, et al. Actualización del consenso sobre el diagnóstico y tratamiento de la sordera súbita idiopática. Acta Otorrinolaringologica, 2018; 70(5): 290-300.

11. KUM RO, et al. Investigation of neutrophil- to- lymphocyte ratio and mean platelet volume in sudden hearing loss. Braz J Otorhinolaryngol, 2015; 81(6).

12. LI G, et al. The Role of Autoimmunity in the Pathogenesis of Sudden Sensorineural Hearing Loss. Hindawi Plasticidade Neural, 2018; 1-9.

13. MAIA NPD, et al. Vestibular evoked myogenic potentials in the prognosis of sudden hearing loss- a systematic review. Braz J Otorhinolaryngol, 2020; 86(2): 247-254.

14. MARTINS MBB, et al. Cochlear implants: our experience and literature review. International Archives of Otorhinolaryngology, 2012; 16(4). 
15. OLIVEIRA WSR, et al. Desenvolvimento e aplicação de uma tecnologia educacional para auxiliar a comunicação entre o deficiente auditivo e enfermeiro: relato de experiência. Revista Eletrônica Acervo Saúde, 2020; 44.

16. RAMOS D, et al. Desenvolvimento da linguagem em crianças com implante coclear: terá o gênero alguma influência? Revista CEFAC, 2015; 17(2).

17. SCARABELLO EM, et al. Language evaluation in children with pre- lingual hearing loss and cochlear implant. Braz $\mathrm{J}$ Otorhinolaryngol, 2020; 86(1): 91-98.

18. TASDÖVEN GE, et al. The place of hyperbaric oxygen therapy and ozone therapy in sudden hearing loss. Braz $\mathrm{J}$ Otorhinolaryngol, 2017; 83(4): 457-463.

19. YONG YI-HO. Contemporary review of the causes and differential diagnosis of sudden sensorineural hearing loss. International Journal of Audiology, 2020; 59(4): 243-253.

20. $\mathrm{YU} \mathrm{GH}$, et al. A comparison of single- dose and multiple divided daily- dose oral steroids for sudden sensorineural hearing loss.Braz J Otorhinolaryngol, 2019; 85(6). 